\title{
HISTOPATHOLOGICAL STUDY OF SALIVARY GLAND TUMOURS
}

\author{
Bhavani $K^{1}$, Roopa Urs A. $N^{2}$, Venkatraman $J^{3}$, Dhananjay S. Kotasthane ${ }^{4}$, Koteeswaran $G^{5}$
}

${ }^{1}$ Assistant Professor, Department of Pathology, Mahatma Gandhi Medical College and Research Institute, Pondicherry. ${ }^{2}$ Assistant Professor, Department of Pathology, Mahatma Gandhi Medical College and Research Institute, Pondicherry. ${ }^{3}$ Assistant Professor, Department of Pathology, Mahatma Gandhi Medical College and Research Institute, Pondicherry. ${ }^{4}$ Professor and HOD, Department of Pathology, Mahatma Gandhi Medical College and Research Institute, Pondicherry. 5Professor, Department of Pathology, Mahatma Gandhi Medical College and Research Institute, Pondicherry.

ABSTRACT
BACKGROUND
Salivary gland tumours are rare neoplasms. It account for $2-6.5 \%$ of all neoplasms of head and neck. They do elicit considerable
medical interest because of their multifaceted clinical presentation, varied histological appearance and associated difficulties in
predicting their prognosis. Classification of salivary gland tumours is essentially based on morphology and histologic aspects of these
tumours.

\section{OBJECTIVE}

To study histopathological types of salivary gland tumours and to classify the tumours according to WHO classification because the classification of salivary gland tumours is absolutely necessary for therapeutic and for prognostic implication.

\section{MATERIALS AND METHODS}

Sixty salivary gland tumours were studied from May 2006 to May 2011. Ten different salivary gland tumours were studied during this study period in MGMC\&RI. In this study, 58 out of 60 were epithelial tumours and 2 were non-epithelial tumours of salivary gland origin. Ten histological types of epithelial and non-epithelial tumours were obtained in this study.

\section{RESULTS}

Out of 60 cases, 58 were epithelial tumours and two were non-epithelial tumours. Overall, 63.3\% of cases in the study were female and $36.7 \%$ were male. Out of 60 cases, 34 were benign, 26 were malignant. $73.3 \%$ of tumours arise from major salivary gland and $26.6 \%$ were found in minor salivary gland. Eleven out of 26 cases of malignant tumours were found in major glands, 15 out of 26 cases were found in minor salivary gland. Out of 60 tumours, 32 arises from parotid, 12 cases from submandibular gland and remaining were from minor salivary gland. Pleomorphic adenoma was the commonest benign tumour forming 28 cases out of 60 . Adenoid cystic carcinoma was the commonest malignant tumour forming 12 cases out of 60 cases. Each one cases of myoepithelioma, schwannoma, adenocarcinoma NOS, polymorphous low-grade adenocarcinoma, undifferentiated carcinoma and lymphoma were studied.

\section{CONCLUSION}

Salivary gland tumours exhibit broad histopathological spectrum. Overlapping features are seen among different salivary gland tumours. Correlation of single and dual differentiation with morphological and immunohistochemistry helps in confirmation of final diagnosis.

\section{KEYWORDS}

Salivary Gland, Benign Tumours, Malignant Tumours, Pleomorphic Adenoma.

HOW TO CITE THIS ARTICLE: Bhavani K, Urs RAN, Venkatraman J, et al. Histopathological study of salivary gland tumours. J. Evolution Med. Dent. Sci. 2016;5(72):5240-5244, DOI: 10.14260/jemds/2016/1187

\section{INTRODUCTION}

Salivary gland tumours are rare neoplasm with annual incidence ranging from 0.4 to 6.5 cases per lakh population. ${ }^{1}$ It accounts to less than $2-6.5 \%$ of all neoplasms of head and neck. $^{2}$ More than forty five types of primary neoplasm are described in salivary gland owing to their varied histopathology despite their low incidence. ${ }^{3}$ They do elicit

Financial or Other, Competing Interest: None.

Submission 17-08-2016, Peer Review 30-08-2016,

Acceptance 01-09-2016, Published 06-09-2016.

Corresponding Author:

Dr. Venkatraman J,

Assistant Professor

Department of Pathology,

Mahatma Gandhi Medical College and

Research Institute, Pondicherry.

E-mail: drvenkatraman1983@gmail.com

DOI: $10.14260 /$ jemds/2016/1187 considerable medical interest because of their multifaceted clinical presentation, varied histological appearance and associated difficulties in predicting their prognosis. ${ }^{1}$

Peak incidence of most of the benign tumours is in the fourth and the fifth decade and malignant is in the sixth and the seventh decade.2,4 More women than men are affected by benign salivary gland tumour. But, malignant tumours are equally divided between the sexes. ${ }^{4} 80 \%$ of parotid gland tumours are benign and $82 \%$ of minor salivary gland tumours were malignant. ${ }^{4}$ Causation of salivary gland tumour is probably multifactorial. Epidemiological study have shown an increased incidence of salivary gland tumour following radiation exposure and patient treated with $\mathrm{I}^{13}$ for the treatment of thyroid disease. 5

Many of the salivary gland tumours can be diagnosed by histopathology alone, but often we face situation such that it is even difficult to differentiate between benign and malignant salivary gland tumours where diagnosis is very crucial as they 
have completely different prognosis and treatment. ${ }^{6}$ Classification of salivary gland tumours is essentially based on morphology and histological aspects of these tumours correlate with normal salivary gland structure. However, the histological similarity does not necessarily imply that a particular tumour arises from the structure it mimics. ${ }^{7}$ Hence, the classification of salivary gland tumours is absolutely necessary for therapeutic and for prognostic implications.

Role of IHC in salivary gland tumours is limited by the fact that most of the common salivary gland tumours with similar morphology tends to arise or differentiate towards same cell line. Thus, there is overlap in IHC pattern among different salivary gland tumours. ${ }^{6,7}$ Histopathology or IHC alone cannot lead us to specific diagnosis in all salivary gland tumours. In the present study, we considered well established histopathology, histochemistry and clinical diagnosis to study the individual salivary gland tumours.

\section{MATERIALS AND METHODS}

The study material included 60 salivary gland tumours diagnosed between May 2006 to May 2011. All salivary gland tumours during this period involving major and minor salivary glands in various sites were studied. Both benign and malignant tumours were studied. Non-neoplastic lesions mimicking salivary gland neoplasm were excluded. The relevant clinical details were noted from the accompanying requisition forms and/or the patient case records. These included age, gender and location and clinical diagnosis. Study included both resected and small biopsy specimen.

Bits were taken from every one centimetre of tumour in resected specimens. Specimen was processed following standard laboratory procedures. 8 The formalin fixed, paraffin embedded sections were then cut into 4 to 6 microns sections by HM320 micro rotary microtome. Subsequently, the slides were stained with Haematoxylin and Eosin (H and E) stain. Special stains like Periodic Acid-Schiff (PAS) and Mucicarmine were performed wherever indicated based on morphological evaluation. Histopathological diagnosis of salivary gland tumour was given based on classical features.

The data were stored and analysed using Microsoft access. Histopathology and histochemistry profile was ascertained to individual tumour after assessing all cases of that particular tumour. Chi-square test was used to analyse the difference in incidence of benign and malignant tumour based on age and gender with $\mathrm{p}$ value $<0.05$ as significant.

\section{RESULTS}

A total of 60 salivary gland tumours over a period of five years from May 2006 to May 2011 were studied. Epithelial tumours of salivary gland origin formed the major part of study with total case number of 58 out of 60 . Ten histological types of epithelial tumours were obtained in the study period. They included pleomorphic adenoma, adenoid cystic carcinoma, mucoepidermoid carcinoma, Warthin tumour, salivary duct carcinoma, basal cell adenocarcinoma, myoepithelioma, adenocarcinoma NOS, Polymorphous low-grade adenocarcinoma and a case of undifferentiated carcinoma. Non-epithelial tumours included in the study were schwannoma and lymphoma.

\section{Age Incidence}

Salivary gland tumours studied were seen in the wide age group ranging from $13 \mathrm{yrs}$. to $67 \mathrm{yrs}$. Most of the tumours were seen in middle age group with mean age of $38.7 \mathrm{yrs}$. for female and 47.6 yrs. for male (Figure 1).

\section{Gender Distribution}

Overall, $63.33 \%$ of cases in the study were female with $36.7 \%$ male cases. 18 out of 26 cases of malignant tumours were female forming $69.2 \%$ of total malignant tumours. Eight out of 26 cases were male and they formed $31 \%$ of total malignant tumours. Among 34 cases of benign tumours in the study, 20 cases of female formed $58.8 \%$ of benign tumours. 14 cases of benign tumours among male formed $41.1 \%$ of total benign tumours (Figure 2).

\section{Site Distribution}

Tumour involved major salivary gland in $73.3 \%$ of cases. $26.6 \%$ of salivary gland tumours were found in minor salivary gland. 28 cases out of 32 cases of parotid tumours were benign. Thus, $87.5 \%$ of cases in parotid gland were benign. Equal distribution of benign and malignant tumour was seen in case of submandibular gland tumours with six each of them among 12 cases of submandibular tumours. 10 cases of salivary gland tumours arising in palate were studied (Figure 3).

\section{Distribution of Various Salivary Gland Tumours}

Majority of the tumours of salivary gland origin were benign as $56.7 \%$ of the total salivary gland tumours were benign and $43.3 \%$ were malignant among total of 60 salivary gland tumours.

Distributions of various benign and malignant salivary gland tumours were illustrated in Table 1 and 2 .

\section{Pleomorphic Adenoma}

Pleomorphic adenoma was the commonest tumour constituting 46\% (28 cases) of all salivary gland tumours and showed female predilection with a male-to-female ratio of 1:1.5. 27 cases of pleomorphic adenoma had capsule leaving one case of recurrent tumour in the total of 28 pleomorphic adenoma cases. Mixed or classical variant was the most common subtype seen in 18 cases of total cases. Eleven out of 18 cases (43\%) of mixed subtype had tubular architecture as major pattern. Cells in island pattern were seen in $68 \%$ of cases. Sheets and discrete cells were seen in 53.5\% and 50\% of cases respectively (figure 4). Fifteen out of 18 cases of mixed subtype had polygonal cells as predominant component followed by plasmacytoid, cuboidal and clear cells. Myxoid was predominant stromal component seen in $53.57 \%$ of cases, chondroid and hyaline was predominant in $25 \%$ and $18 \%$ cases respectively.

\section{Adenoid Cystic Carcinoma}

Twelve cases of adenoid cystic carcinoma were studied constituting $20 \%$ of all salivary gland tumours of which 10 were arising from minor salivary glands and all twelve tumours were having infiltrating borders. Cribriform was major architectural pattern seen in ten cases out of twelve cases followed by tubular and island pattern. Predominant cases were showing basaloid rich cells with the combination of myxoid and hyaline stroma.

\section{Mucoepidermoid Carcinoma}

Mucoepidermoid carcinoma was third most common tumour $(10 \%)$ with equal distribution of origin in major and minor 
salivary glands. Mean age of presentation was 42.17 years and male-female ratio was found to be 1:1.5. Island pattern were the predominant pattern observed in high and intermediate grades of MEC seen in three out of six cases of MEC. Mucinous cells were predominantly seen in two cases of low-grade MEC and squamous cells were predominant cell in rest of four cases of MEC, which included one high grade and three intermediate grade MEC.

\section{Warthin Tumour}

Warthin tumour was the second most common benign salivary gland tumour constituting $6 \%$ of all salivary gland tumours showing equal distribution among male and female population. Mean age of presentation was 42 years. All cases of Warthin tumour in the study had well-defined margin. Three cases of Warthin tumour had intact capsule. Whereas one case of stroma rich subtype of Warthin tumour did not show capsule. Oncocytes along with lymphoid aggregates were the predominant epithelial cell type in all cases of Warthin tumour. Basaloid cells lining these oncocytes were observed in all cases. One case had stratified squamous epithelial lining in addition.

\section{Basal Cell Adenocarcinoma}

Two cases of basal cell adenocarcinoma with infiltrating borders without intact capsule. Mean age of presentation was 45 years and shows male preponderance.

\section{Salivary Duct Carcinoma}

Two cases of salivary duct carcinoma in elderly males aged 60 and 62 years were studied. Both tumours were from submandibular gland. Predominant pattern observed in both cases were ductal architecture in addition to islands.

\section{Other Tumours in the Study}

Six different tumours with single incidence were also studied. These included myoepithelioma adenocarcinoma NOS, polymorphous low-grade adenocarcinoma, undifferentiated carcinoma, schwannoma and Non-Hodgkin Lymphoma (NHL).

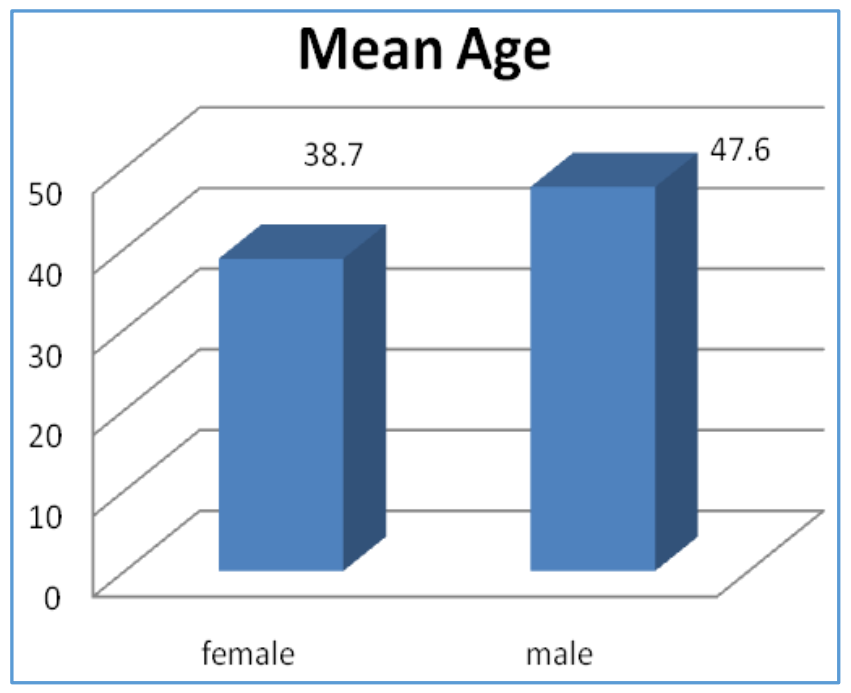

Fig. 1: Mean Age and Gender Distribution of Salivary Gland Tumours

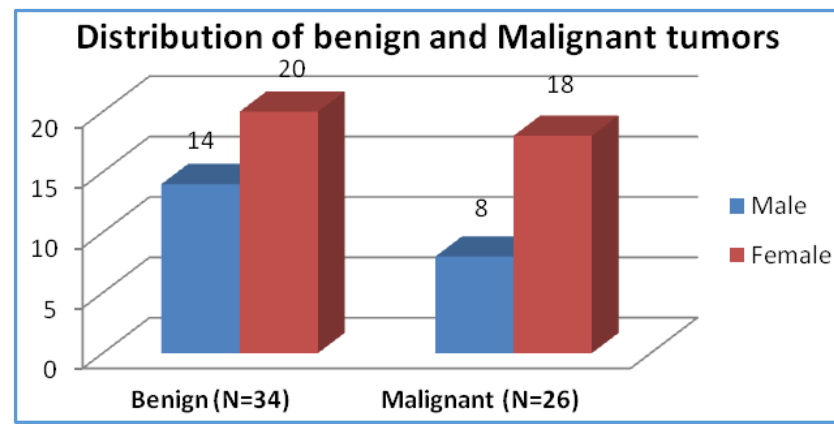

Fig. 2: Gender Wise Distribution of Various Benign and Malignant Salivary Gland Tumours

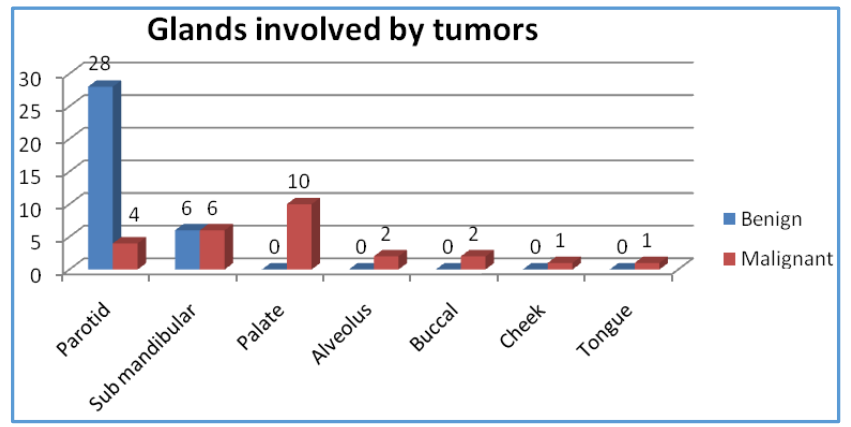

Fig. 3: Site Wise Distribution of Benign and Malignant Tumours

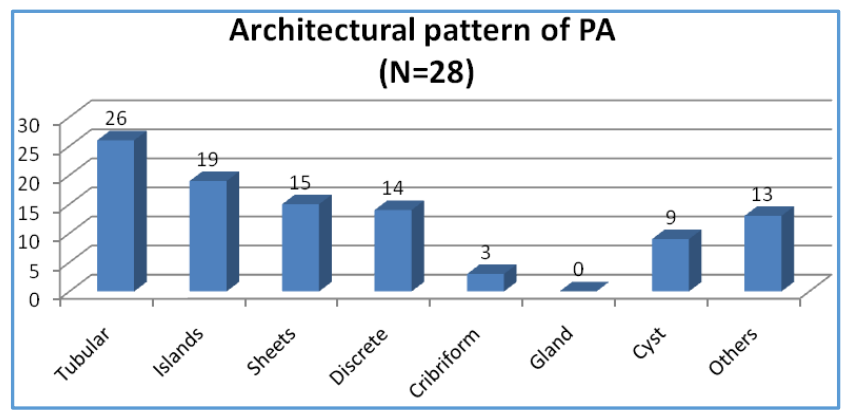

Fig. 4: Architectural Patterns of Pleomorphic Adenoma

\begin{tabular}{|c|c|c|}
\hline Tumour & No. of Cases & \% \\
\hline Pleomorphic Adenoma & 28 & 82.35 \\
\hline Warthin Tumour & 4 & 11.76 \\
\hline Myoepithelioma & 1 & 2.94 \\
\hline Non-Epithelial Tumour & 1 & 2.94 \\
\hline
\end{tabular}

Table 1: Distribution of Benign Salivary Gland Tumours

\begin{tabular}{|c|c|c|}
\hline Tumour & $\begin{array}{c}\text { No. of } \\
\text { Cases }\end{array}$ & \% \\
\hline Adenoid Cystic Carcinoma & 12 & 46.15 \\
\hline Mucoepidermoid Carcinoma & 6 & 23.07 \\
\hline Basal Cell Adenocarcinoma & 2 & 7.69 \\
\hline Salivary Duct Carcinoma & 2 & 7.69 \\
\hline Adenocarcinoma NOS & 1 & 3.84 \\
\hline $\begin{array}{c}\text { Polymorphous Low-Grade } \\
\text { Adenocarcinoma }\end{array}$ & 1 & 3.84 \\
\hline Undifferentiated Carcinoma & 1 & 3.84 \\
\hline Non-Epithelial Malignant Tumour & 1 & 3.84 \\
\hline Table 2: Distribution of Malignant Salivary Gland \\
Tumours \\
\hline
\end{tabular}




\section{DISCUSSION}

Salivary gland neoplasms are rare tumours accounting for less than $2 \%$ of all tumours in the body. ${ }^{9}$ Relative proportion of malignant and benign tumours was near to the data published in the third series of Armed Forces Institute of Pathology.10 Parotid gland involvement was less as compared to study of Eveson et al and overall range mentioned in standard literature states it to be between 65 to $80 \% .{ }^{11}$

Many of the studies have mentioned that chances of salivary gland tumour to be malignant is more in minor salivary glands. ${ }^{11,12}$ In our study, also major salivary gland had significantly higher number of benign tumours and all minor salivary gland tumours were malignant.

In our study, there was a female preponderance with $63.3 \%$ of tumours in female. Eveson et al study also had shown female preponderance in all salivary gland tumours except in case of Warthin tumour. ${ }^{11}$ In our study, salivary gland tumours were more commonly seen in middle-aged female and a decade later in male, which is similar to Eveson et al study. ${ }^{11}$

In our study, pleomorphic adenoma was the commonest salivary gland tumour constituting $47 \%$ of all tumours and $82.35 \%$ of benign tumours. In AFIP study, however, it account less than one half of all tumours. ${ }^{10}$ Adenoid cystic carcinoma was the second most common tumour in our study, which accounted for $20 \%$ of all cases and $46 \%$ of malignant tumours. Other studies including Eveson et al had similar findings with adenoid cystic carcinoma being second common salivary gland tumour. ${ }^{4,10,11}$

\section{Pleomorphic Adenoma}

Study done by Eveson and Cawson also showed female preponderance with highest incidence of Pleomorphic adenoma in parotid gland.11 Mean age of incidence was slightly lower in our study compared to other studies, which was between fourth to fifth decade. ${ }^{10}$ Three cases out of twenty eight cases had focal infiltration in capsule and surrounding normal gland. Such tumours are more prone for recurrence. Such satellite lesions are mentioned in $72 \%$ of Pleomorphic adenoma in study of Paris et al.13 This study also mentions the importance of parotidectomy as these capsular infiltration characteristically leads to recurrence in case of enucleation. ${ }^{13}$ Mixed subtype was the predominant type of Pleomorphic adenoma in this study. It constituted $61 \%$ of Pleomorphic adenoma followed by equal distribution of cellular and stroma rich subtype. Fabio et al study showed $21 \%$ of classic or mixed subtype following stroma rich and cellular subtype, which were $52.4 \%$ and $36.5 \%$, respectively. ${ }^{4}$ Stroma rich subtype is more increasingly associated with extension to capsule and surrounding tissue. They have increased tendency for recurrence. Thus, further subclassification of Pleomorphic adenoma is important. ${ }^{4}$

Fabio et al study, which states that plasmacytoid cells were most commonly seen, however, in our study, polygonal cells were less predominantly seen followed by plasmacytoid cells. ${ }^{4}$ In our study, out of 10 different salivary gland tumours, plasmacytoid cells were exclusively seen in both pleomorphic adenoma and myoepithelioma. This observation is similar to Lomax Smith study. ${ }^{14}$ Squamous metaplasia was commonest metaplasia observed in our study, which has been reported in many studies including Fabio et al. ${ }^{4}$

\section{Adenoid Cystic Carcinoma}

Similar to the several studies published recent past, Adenoid cystic carcinoma was found to be the second most common malignant salivary gland tumour.10 Parotid gland was the commonest site followed by submandibular gland and palate as mentioned in other studies.4,10 However, in our study, palate was the most common site. Peripheral nerve invasion is characteristic feature of adenoid cystic carcinoma. 15 This feature was also seen in our study. In our study, majority of the tumours were of grade 1 with total of $50 \%$ of adenoid cystic carcinoma. Grade 2 and 3 were equally distributed (i.e.) $25 \%$ of each. This observation was similar to other studies. ${ }^{4,10,11}$ Cribriform architecture was the most common pattern observed in all cases of adenoid cystic carcinoma in our study as mentioned in other studies.4,10,11 Similar to our study, Basaloid type of cells are the predominant cell type found in adenoid cystic carcinoma of other studies.,10

\section{Mucoepidermoid Carcinoma}

Mucoepidermoid carcinoma was the most common malignant tumour in other studies.16 However, mucoepidermoid carcinoma was the second most common malignant tumour in our study following adenoid cystic carcinoma. Minor glands were equally involved as compared to major glands, which are known in several other studies. ${ }^{10}$ Similar features were also seen in our study. Mucoepidermoid carcinoma was graded into three categories based on Goode et al.16 Island or nest pattern was formed by epidermoid and intermediate cells. This was the common and predominant pattern in intermediate and high-grade tumour with predominance of epidermoid cells in our study, which is similar to Goode et al study. ${ }^{16}$ Mucous cells were the predominant cell type in low grade. Epidermoid or squamous cells with intermediate cells are the predominant cell type in high and intermediate-grade tumours.4,10 In our study, Clear cells apart from mucous cells were seen to form low-grade Mucoepidermoid carcinoma. Squamous cells were more commonly seen than intermediate cells in high and intermediate-grade tumours.

\section{Warthin Tumour}

Warthin tumour was the second commonest benign tumour in our study. It is a common benign tumour in other studies also. ${ }^{2}$ It is known to be limited to parotid gland though very rare exceptions have been reported in other studies. ${ }^{10}$ In our study, all four cases were from parotid gland. Marked male preponderance is known in contrast to other salivary gland tumours. However, recent studies have shown decreased predilection of Warthin tumour among male. ${ }^{10}$ Our study has two cases with equal distribution among male and female. In AFIP study material (1996), average age of presentation was about 62 yrs. with range of 29 to 88 yrs. ${ }^{10}$ In our study with only four cases average age was much lower, i.e. 42.16 yrs. with range of 30 to 55 years. Lymphoid stroma was the most striking feature of all these tumours as in other studies.10,17 Oncocytes are one of the classical features seen with lymphoid stroma. ${ }^{4,17}$

\section{Basal Cell Adenocarcinoma}

Two cases of Basal cell adenocarcinoma were diagnosed in our study. Nearly, $90 \%$ of these tumours occur in parotid gland. 18 However, in our study, one case was seen in submandibular gland and the other was seen in minor salivary gland. None of the cases were from parotid gland. Formation of Islands was the predominant architecture in both the cases. One of them had neural invasion as seen in nearly 25 to $35 \%$ of basal cell adenocarcinoma in other studies. ${ }^{10,18}$ 


\section{Salivary Duct Carcinoma}

Salivary duct carcinoma is a rare tumour with low incidence. ${ }^{10}$ We had only two cases of SDC among 60 cases of salivary gland tumours.

\section{Myoepithelioma}

Single case of myoepithelioma was seen in our study period. Parotid gland predilection is well known in myoepithelioma with predominant sheets and interlacing fascicular architecture. ${ }^{19}$ The single case in our study was also from the same site with same architecture.

\section{Adenocarcinoma NOS}

One case of adenocarcinoma diagnosed in our study was highgrade malignant tumour in minor salivary gland. This tumour had vague glandular pattern with lack of recognisable feature of other salivary gland tumours. ${ }^{10}$

\section{Polymorphous Low-Grade Adenocarcinoma}

Only single case of PLGA was diagnosed in our study period, which is much less in number compared to other studies where it is found to represent $20-25 \%$ of all malignant tumours. 10

\section{Carcinoma Ex Pleomorphic Adenoma}

Two cases of carcinoma ex pleomorphic adenoma were studied. Both cases were seen in elderly patients. One of the case was arising in pleomorphic adenoma of submandibular gland and other case was undifferentiated carcinoma arising from parotid gland. These features were similar to other studies. ${ }^{20}$ Both tumours showed focal features of classical pleomorphic adenoma with extensive areas of hyalinisation, which is one of the criteria for diagnosis of carcinoma ex pleomorphic adenoma. 4,10

\section{Non-Epithelial Tumours of Salivary Gland Schwannoma}

Schwannoma in parotid gland have morphological similarity with spindle cell type of myoepithelioma. However, characteristic Antoni A and Antoni B pattern was seen in our case of parotid schwannoma, which made diagnosis obvious.

\section{Non-Hodgkin's Lymphoma}

One case of lymphoma studied was seen in parotid gland. It was a case of diffuse large B cell lymphoma. Biopsy from enlarged cervical lymph node also showed features of DLBCL.

\section{CONCLUSION}

Salivary gland tumours exhibit broad histopathological spectrum. Overlapping features are seen among different salivary gland tumours on $\mathrm{H}$ and $\mathrm{E}$ sections. Diagnosis cannot be given based on one single feature. Correlation of single and dual differentiation with morphological, luminal and abluminal categories help in confirmation of final diagnosis of various salivary gland tumours.

\section{REFERENCES}

1. Sun EC, Curtis R, Melbye M, et al. Salivary gland cancer in the United States. Cancer Epidemiol Biomarkers Prev 1999;8(12):1095-100.

2. Spiro RH. Salivary neoplasms: overview of a 35-year experience with 2,807 patients. Head and Neck Surg 1986;8(3):177-84.
3. Branes J, Eveson J, Reichert P, et al. eds. World Health Organisation, classification of tumours. Head and neck tumours. Lyon: IARC Press 2005.

4. Ito FA, Jorge J, Vargas PA, et al. Histopathological findings of pleomorphic adenomas of the salivary glands. Med Oral Patol Oral Cir Bucal 2009;14(2):E57-61.

5. Pinkston JA, Cole P. Incidence rates of salivary gland tumours: results form a population-based study. Otolaryngol Head Neck Surg 1999;120(6):834-40.

6. Chek W, Chan JKC. Salivary gland tumours. In: Fletcher CDM, ed. Diagnostic histopathology of tumours. $3^{\text {rd }}$ edn. China: Churchill Livingstone 2000:239-316.

7. Dardick I, van Nostrand AW. Morphogenesis of salivary gland tumours. A prerequisite to improving classification. Pathol Annu 1987;22(Pt 1):1-53.

8. Anderson G, Bancroft JD. Tissue processing and microtomy including frozen. In: Bancroft JD, Gamble M, eds. Theory and practice of histological techniques. $5^{\text {th }}$ edn. China: Churchill Livingstone 2002:85-108.

9. Mark WL, Kumar V. Head and neck. In: Kumar V, Abbs AK, Fausto N, eds. Robbins and cotran pathologic basis of diseases. $8^{\text {th }}$ edn. Philadelphia: Elsevier 2010:739-62.

10. Ellis GL, Auclair PL. Tumours of the salivary glands. Atlas of tumour pathology. $3^{\text {rd }}$ series, fascicle $17,1^{\text {st }}$ edn. Washington DC: Armed Forces Institute of Pathology 1996:27-30.

11. Eveson JW, Cawson RA. Salivary gland tumours. A review of 2410 cases with special reference to histological types, site and age and sex distribution. J Pathol 1985;146(1):518.

12. Eversole L. Salivary gland pathology In: Fu YS, Wening BM, Abmeyor E, et al. eds. Head and neck pathology with clinical correlation. $1^{\text {st }}$ edn. Pennsylvania: Churchill Livingstone 2001:242-92.

13. Paris J, Facon F, Chrestian MA, et al. Pleomorphic adenoma of the parotid: histopathological study. Ann Otolaryngol Chir Cervicofac 2004;121(3):161-6.

14. Lomax-Smith JD, Azzopardi JG. The hyaline cell: a distinctive feature of mixed salivary tumours. Histopathology 1978;2(2):77-92.

15. Friedrich RE, Bleckmann V. Adenoid cyctic carcinoma of salivary and lacrimal gland origin: localization, classification, clinical pathological correlation, treatment results and long-term follow-up control in 84 patients. Anticancer Res 2003;23(2A):931-40.

16. Goode RK, Auclair PL, Ellis GL. Mucoepidermoid carcinoma of the major salivary glands: clinical and histopathological analysis of 234 cases with evaluation of grading criteria. Cancer 1998;82(7):1217-24.

17. Taxy JB. Necrotising squamous/mucinous metaplasia in oncocytic salivary gland tumours. A potential diagnostic problem. Am J Clin Pathol 1992;97(1):40-5.

18. Ellis GL, Wiscovitch JG. Basal cell adenocarcinomas of the salivary glands. Oral Surg Oral Med Oral Pathol 1990;69(4):461-9.

19. Kawashima Y, Kobayashi D, Ishikawa N, et al. A case of myoepithelioma arising in an accessory parotid gland. J Laryngol Otol 2002;116(6):474-6.

20. Eneroth CM, Zetterberg A. Malignancy in pleomorphic adenoma. A clinical and microspectrophotometric study. Acta Otolaryngol 1974;77(6):426-32. 